\section{Bipolar disorder}

\author{
By Joe Bouch
}

Joe Bouch

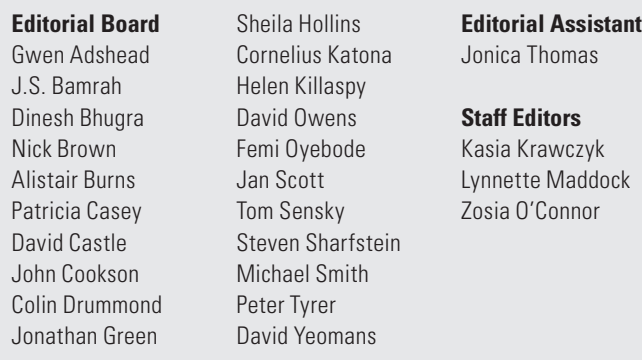

\section{Subscriptions}

Advances Volume 16, 2010 (six issues)

(full airmail £19/US\$34 extra)

Members of the
Royal College
of Psychiatrists Non-members Institutions

\begin{tabular}{lccc}
\hline Print (+free online) & & & \\
Europe (\& UK) & $£ 62$ & $£ 130$ & $£ 141$ \\
USA & US\$110 & US $\$ 205$ & US\$243 \\
Elsewhere & $£ 69$ & $£ 140$ & $£ 152$
\end{tabular}

Online (only)

Worldwide

£39/US\$63 £103/US\$155 £128/US\$199

Payment may be made by cheque/money order, by Access/Master Card/ Visa/American Express, or by UNESCO coupons. EC subscribers: please supply your Member State Code and Value Added Tax (VAT) number.

Payment should be made to Maney Publishing, Suite 1C, Joseph's Well, Hanover Walk, Leeds LS3 1AB, UK (tel: +44 (0)113 243 2800; fax: +44 (0)113 386 8178; email: subscriptions@maney.co.uk). For subscriptions in North America, please contact Maney Publishing North America, 875 Massachusetts Avenue, 7th Floor, Cambridge, MA 02139, USA (tel: 866 2975154 (toll-free); fax: 617354 6875; email: maney@maneyusa.com).

Continuing professional development (CPD) Those wishing to register for CPD with the Royal College of Psychiatrists should contact the CPD unit (tel: +44 (0)20 72352351 , ext. 108 or 112). There is no charge for participation in the CPD scheme for Members, Fellows and Affiliates of the College.

CPD Online The College also publishes an interactive online learning facility for CPD in psychiatry. Further details, sample modules and subscription information can be viewed at www.psychiatrycpd.co.uk. Discounts are available for Advances subscribers.

Correspondence Letters submitted for publication should be emailed to Dr Joe Bouch at apt@rcpsych.ac.uk or posted to Advances in Psychiatric Treatment, Royal College of Psychiatrists, 17 Belgrave Square, London SW1X 8PG.

Printed by Henry Ling Ltd, 23 High East Street, Dorchester, Dorset DT1 1 HD.

(C) The Royal College of Psychiatrists 2010. Published by the Royal College of Psychiatrists, a charity registered in England and Wales (228636) and in Scotland (SC038369). Unless so stated, material in Advances in Psychiatric Treatment does not necessarily reflect the views of the Editor or the Royal College of Psychiatrists. The publishers are not responsible for any errors of omission or fact.

The College crest is a registered trade mark of the Royal College of Psychiatrists.

ISSN 1355-5146
Three years ago a provocative editorial in the British Journal of Psychiatry argued that we should rethink the place of bipolar disorder in psychiatry. Rather than schizophrenia, bipolar disorder should be the 'dominant paradigm - the heartland condition' (Goodwin 2007). One of the arguments was that the course of bipolar disorder 'allows a much more meaningful distinction' between acute and long-term care. Perhaps so, but for many clinicians the waters of clinical practice have become muddied over the past three years. Even though, as Goodwin Geddes noted, 'we are not embarrassed to tell patients they have bipolar disorder', who would have foreseen that the condition, endorsed by celebrities, would acquire a cachet, coming to be seen as 'a favourable and even desirable diagnosis' - a diagnosis associated with creativity and higher social status which, given the choice, one would 'keep' (Chan 2010)? Who would have guessed that one day The Psychiatrist's front cover would bear the legend 'I want to be bipolar'? Perhaps for clinicians the crunch is whether bipolar disorder should be defined narrowly as a severe mental illness or not. Might it better be conceived of as a heterogeneous group of disorders including 'softer' elements - the bipolar spectrum? The implications are enormous, given that the estimated prevalence for bipolar-spectrum illness is a staggering $8.3 \%$ of the population.

Saunders \& Goodwin (pp. 318-328) consider this and a number of key clinical issues in light of the evidence. What is the mean age at onset? (They note the 'considerable downward shift' reported in studies over the past two decades.) Is early diagnosis possible? A third of individuals wait 10 years for an accurate diagnosis. Is early intervention possible? Given the important link between suicide and the early stages of the illness, harm reduction might be possible (Jamison 2005). What is the minimum duration of a hypomanic episode? Some argue that it should be less than the 4 days required by DSM-IV. This has crucial significance in establishing the breadth of the spectrum. How should the clinician respond to subsyndromal symptoms? These are common and, although depressive symptoms cause impairment, subsyndromal hypomanic symptoms actually enhance functioning. And lastly comorbidity, almost the sine qua non of bipolar disorder, with huge prevalences of alcohol misuse and personality disorder in particular.

\section{Developmental dyslexia}

My Editor's pick for this issue is the article by Thambirajah (pp. 380-387). It could serve as an exemplar for a clinical article for Advances - clear prose, rich clinical illustrations, signposting further reading and resources, practical tips for clinicians and memorable imagery. I will not quickly forget 'the Matthew effect' (the rich get richer and the poor get poorer) in dyslexia - fear of failure leads to avoidance of reading and consequently falling even further behind.

Chan D, Sireling L (2010) 'I want to be bipolar' ... a new phenomenon. Psychiatrist 34: 103-5.

Goodwin GM, Geddes JR (2007) What is the heartland of psychiatry? British Journal of Psychiatry 191: 189-91.

Jamison KR, Hawton K (2005) The burden of suicide and clinical suggestions for prevention. In Prevention and Treatment of Suicidal Behaviour (ed K Hawton): 183-96. Oxford University Press. 